\title{
COMUNIDADES DE PRÁTICA: UM ESTUDO DE CASO REDARTE/RJ
}

\section{COMUNIDADES DE PRÁCTICA: UN ESTUDIO DE CASO REDARTE/RJ}

Elisete de Sousa Melo - elisetemel@hotmail.com
Mestra em Biblioteconomia UNIRIO. Bibliotecária da

TRANSPETRO/RJ

Mariza Costa Almeida - almeida.mariza@globo.com Doutora em Engenharia de Produção pela UFRJ. Professora Adjunta do PPGB UNIRIO.

\begin{abstract}
RESUMO
Introdução: As redes desempenham um papel cada vez mais importante na sociedade.

Objetivo: Identificar e analisar quais características da Rede de Bibliotecas e Centros de Informação em Arte no Estado do Rio de Janeiro (REDARTE/RJ) se assemelham às de comunidades de prática $(\mathrm{CoP}) \mathrm{e}$, caso positivo, verificar se as características observadas podem contribuir para a maior integração das ações desenvolvidas pelos profissionais de informação em Arte e suas instituições.

Metodologia: Estudo de caso baseado em pesquisa do tipo descritiva e exploratória com abordagem qualitativa e quantitativa que utilizou para coleta de dados pesquisa documental, entrevista e aplicação de questionário. Identifica pontos fortes e pontos de melhoria.

Resultados: Constata-se que a REDARTE/RJ pode ser caracterizada como uma comunidade de prática, pois possui as características essenciais deste tipo de organização: o domínio, a comunidade e a prática, nas suas atividades, produtos e serviços.

Conclusões: Os pontos fortes e melhoria são identificados, bem como são apresentadas recomendações estratégias de CoP para potencializar as ações da Rede.

Palavras-chave: Comunidades de prática. Gestão do conhecimento. Informação em Arte. Redes de bibliotecas. Centros de informação. REDARTE/RJ.
\end{abstract}




\section{INTRODUÇÃO}

O papel dos profissionais da informação (bibliotecários, arquivistas, museólogos, entre outros) no Brasil, ainda tem pouca visibilidade nas instituições, e geralmente, os recursos destinados para o setor de informação é escasso. Sendo assim, em algumas áreas de conhecimento, os profissionais da informação se estruturam em grupos e redes para trocar experiências e compartilhar conhecimento.

Os agrupamentos, geralmente, iniciam de maneira informal e com o passar do tempo se estruturam de modo a formalizarem suas atividades. Assim, o conhecimento gerado por estes grupos, redes, comunidades, seja qual for o rótulo atribuído ganha espaço no mercado de trabalho.

Para que o conhecimento gerado possa fluir e se multiplicar é necessário ambiente que propicie condições para isto. No ambiente organizacional é comum as instituições utilizarem instrumentos de Gestão do Conhecimento (GC) para motivar o compartilhamento do conhecimento entre seus profissionais.

A GC tem por objetivo identificar, gerar, captar, registrar, disseminar, compartilhar o conhecimento tácito das organizações e colaborar com a cultura e memória organizacional (IFLA, 2014). A definição da IFLA sobre GC vem de encontro com o entendimento de Terra (2007) sobre o tema, na medida em que para este autor tratam-se de práticas gerenciais, que procuram incentivar o compartilhamento de conhecimentos e a troca de experiência entre as pessoas de uma organização. Assim sendo, a estrutura que proporciona ambiente favorável a partilha de conhecimento, informações e experiências são as comunidades de prática.

As comunidades de prática são grupos de pessoas que compartilham um interesse ou "paixão" por determinado assunto e que pretendem desenvolver competências de seus participantes de forma a fazer e aprender fazê-lo de um modo melhor, assim gera e troca conhecimento (WENGER; McDERMOTT; SNYDER, 2002). 
Em muitas áreas de conhecimento os profissionais da informação se unem para melhor desempenhar suas funções. Segundo a Special Libraries Associations (SLA, 2003) os profissionais utilizam estrategicamente informação em seu trabalho para colaborar com a missão de sua instituição. Estes profissionais fazem isso através do desenvolvimento, implantação e gestão de recursos de informação e serviços.

Os profissionais da informação que trabalham com informação em Arte se deparam com a necessidade de trocar experiências para melhor gerenciar o ambiente informacional em Arte. O escopo da informação em Arte é muito amplo, pois incorpora os aspectos da obra em si, bibliográficos e do material gerado sobre aquela obra de arte.

Sendo assim, há uma variedade de documentos que na visão de Pinheiro e Gonzalez de Gomez (2000, p. 8) são constituídos por

Informação em Arte tanto engloba os aspectos formais, descritivos, quanto os de "atributos e relações das obras de Arte com a história", pois estão presentes, como em todo esforço de representação, a relação de espaço e tempo, certa historicidade e historiografia.

Trocar experiências e conhecimento, e superar o estado de carência documental e informacional das bibliotecas e centros de informação em Arte foram as motivações para a criação em 1995 da Rede de bibliotecas e centros de informação em Arte no Estado do Rio de Janeiro - REDARTE/RJ. Idealizada por Solange Zuñiga, Diretora do Departamento de Pesquisa e Documentação da Fundação Nacional de Artes (FUNARTE), e que convida Helena Dodd Ferrez, Coordenadora do mesmo departamento para assumir a coordenação do grupo em formação.

Em 2006 a rede é oficialmente qualificada como uma associação civil de natureza cultural, sem fins lucrativos, sendo uma de seus objetivos promover o acesso do público interessado em Arte aos itens informacionais, em qualquer suporte ou meio eletrônico, existentes nas Unidades Integrantes da REDARTE/RJ, respeitando a disponibilidade de 
cada uma.

Esta pesquisa tem como objetivo identificar e analisar quais se características da Rede de Bibliotecas e Centros de Informação em Arte no Estado do Rio de Janeiro (REDARTE/RJ) se assemelham às de comunidades de prática (CoP) e, caso positivo, verificar se as características observadas podem contribuir para a maior integração das ações desenvolvidas pelos profissionais de informação em Arte e suas instituições.

Este artigo além da presente introdução, apresenta na seção dois os fundamentos teóricos que caracterizam as Comunidades de prática enquanto na seção 3 discorre sobre a Teoria da Difusão da inovação. A seção 4 aborda a metodologia utilizada para a realização da pesquisa. $A$ seção 5 é composta pela análise dos resultados; e, na seção 6 estão incluídas as considerações finais.

\section{COMUNIDADES DE PRÁTICA: CARACTERÍSTICAS, INDICADORES, FATORES DE SUCESSO}

Comunidade de prática (CoP) pode ser caracterizada com um dos instrumentos de Gestão do Conhecimento (GC) nas organizações e vice-versa. Observa-se em relação à GC e as bibliotecas universitárias a descrição defendida por Charles Townley (2001) que afirma "a Gestão do Conhecimento visa a dar suporte às comunidades de práticas na criação e uso do conhecimento".

Segundo Wenger (2010, p.1) o conceito de comunidade de prática surge no final dos anos 80 , quando Wenger e Lave procuram demonstrar a natureza social da aprendizagem humana com base na antropologia e teoria social.

Wenger (1998) e Wenger, McDermott e Snyder (2002) afirmam que comunidades de prática "são grupos de pessoas que compartilham um interesse ou "paixão" por determinado assunto que pretendem desenvolver competências de seus participantes de forma a fazer e aprender fazê-lo de um modo melhor, assim gera e troca conhecimento". 
São em número de três as características pilares que definem uma comunidade de prática: o domínio, a comunidade e a prática (WENGER, 1998; MCDERMOTT; SNYDER, 2002).

Wenger, McDermott e Snyder (2002) consideram que:

O domínio - o embasamento é comum a todos. Com o passar do tempo é o que institui uma identidade para o grupo e define o foco da discussão na comunidade. Legitima a comunidade por afirmar seus propósito e valor para os membros e as partes interessadas. Existe uma competência compartilhada que diferencia seus membros de outros. É algo dinâmico que se atualiza com o mundo social e a própria comunidade.

A comunidade - é constituída pelo grupo de pessoas que interagem, colaboram, compartilham informações e conhecimento. Estabelecem relações de forma a aprenderem um com os outros. Desenvolvem um sentimento de pertencer a algo, de estar engajadas em algo que contribua para melhoria de suas atividades. O grupo apreende junto e constrói em conjunto, o que pode resultar em produtos e serviços. A interação cria uma "common history and communal identity", mas isto não quer dizer que sempre exista harmonia. Daí a importância do líder de uma comunidade estar preparado para acompanhar a evolução da mesma.

A prática - os membros de uma comunidade de prática são os praticantes. Desenvolvem um repertório compartilhado de recursos: experiências, ideias, histórias, ferramentas, estilo e formas de lidar com problemas recorrentes, documentos compartilhados pelos membros. Isto leva tempo e interação sustentada. Os participantes estabelecem rotinas para organização do conhecimento de forma que possa ser útil para cada um em suas unidades. E o resultado é um produto da comunidade e não do indivíduo.

Para Wenger, McDermott e Snyder (2002) o equilíbrio dos três atributos deve ser mantido para orientar o desenvolvimento, a manutenção e a sustentabilidade de comunidades de prática numa organização e extramuros.

Observa-se a existência de um conjunto de aspectos que podem contribuir para uma comunidade de prática, como destaca Melo (2015, p. 33) "[...] ao mesmo tempo em que é fundamental a presença dos três elementos é importante que se destaque os critérios e fatores de identificação de uma comunidade de prática." 
Determinados aspectos são indicadores de tendências a uma estrutura de comunidade de prática, por isto, é relevante a elaboração de um diagnóstico. Segundo Wenger (1998, p.125-126) devem ser levados em consideração os 14 indicadores determinantes para estruturar uma CoP.

1. As relações mútuas sustentáveis - harmoniosas ou conflituosas;

2. Formas compartilhadas de engajar-se em fazer as coisas juntos:

3. O rápido fluxo de informações e propagação da inovação;

4. Ausência de preâmbulos introdutórios, como se conversas e interações foram apenas a continuação de um processo contínuo;

5. Configuração muito rápida de um problema a ser discutido;

6. Sobreposição substancial entre as descrições de quem pertence dos participantes;

7. Conhecer o que os outros sabem o que eles podem fazer, e como eles podem contribuir para uma empresa;

8. Identidades mutuamente definidoras;

9. A capacidade de avaliar a adequação das ações e produtos;

10. Ferramentas específicas, representações e outros artefatos;

11. A sabedoria local, histórias compartilhadas, piadas, sabendo riso;

12. Jargão e atalhos para as comunicações, bem como a facilidade de produzir novos;

13. Certos estilos reconhecidos como a indicação de membros; $।$

14. Um discurso compartilhado refletindo certa perspectiva sobre o mundo.

Nota-se numa análise mais detalhada que os indicadores de Wenger (1998) complementam as características de comunidades de prática definidas por Wenger (1998) e Wenger, McDermott e Snyder (2002).

Existem outros aspectos determinantes que podem contribuir para o sucesso e a sustentabilidade de uma comunidade de prática. São os fatores críticos de sucesso elencados por McDermott (2001). O autor afirma que para se alcançar sucesso com uma comunidade deve-se observar 10 fatores, os quais estão distribuídos em quatro desafios. Os desafios são da gestão, da comunidade, o técnico e o pessoal ao iniciar 
e apoiar comunidades que tenham o perfil para compartilhar conhecimento tácito (as experiências e conhecimento que todas as pessoas têm sobre determinado assunto) e estão propensas a pensar juntos na melhor prática para o seu dia-a-dia.

O desafio de gestão é o de comunicar que a organização realmente valoriza a partilha de conhecimentos (fatores: liderança, membros e patrocínio). O desafio da comunidade é criar valor real para seus membros e garantir que as ações sejam o pensamento de todos os membros (ambiente social, regras e confiança). O desafio técnico é a concepção de sistemas humanos e informacionais que não só torna as informações disponíveis, mas ajuda aos membros da comunidade pensar juntos (tecnologia como suporte). E o desafio pessoal que é estar aberto para as ideias dos outros e manter uma sede para o desenvolvimento da prática da comunidade (participação efetiva).

\section{TEORIA DA DIFUSÃO DE INOVAÇÃO}

A iniciativa de mudar algo, fazer algo que difere do que a maioria faz, provoca esforço e comprometimento em provar que a mudança é para melhorar um processo, um serviço, uma situação, etc.

A mudança de um produto ou serviço pode ser considera um ato inovador, significa inovação dentro de um contexto.

Segundo o Manual de Oslo (OECD, 1997) inovação é "implementação de um produto (bem ou serviço) novo ou significativamente melhorado; um processo; um novo método de marketing; ou um novo método organizacional nas práticas de negócios, na organização do local de trabalho ou nas relações externas." A Organisation for Economic Co-operation and Development (OECD) alicerça sua publicação em quatro escopos: abrangência setorial, a inovação no nível da empresa, inovação tecnológica de produto e de processo e difusão da inovação. 
Difusão da inovação foi o escopo abordado na pesquisa que deu origem o presente artigo. Para tratar do escopo recorreu-se a teoria da difusão de inovação de Rogers $(1983,2003)$.

Segundo Rogers (2003) a difusão é um processo pelo qual ocorre a alteração na estrutura e função de um sistema social. Enquanto o sistema social é considerado como sendo um conjunto de unidades inter-relacionadas que se unem para resolver um problema e atingir uma meta comum (ROGERS, 2003).

Neste sentido a difusão pode ser um agente de mudança numa organização, numa área de negócio, no modo de agir de profissionais de determinada área do conhecimento. Isto é, quando novas ideias são inventadas (criação-inovação), difundidas (difusão) e são adotadas (expansão) ou rejeitadas, levando a certas consequências ocorre à mudança.

\section{METODOLOGIA}

O presente artigo é resultante da dissertação realizada no contexto do Programa de Pós-graduação em Biblioteconomia da UNIRIO realizada por Melo (2015) com o objetivo identificar e analisar quais se características da Rede de Bibliotecas e Centros de Informação em Arte no Estado do Rio de Janeiro (REDARTE/RJ) se assemelham às de comunidades de prática (CoP) e, caso positivo, verificar se as características observadas podem contribuir para a maior integração das ações desenvolvidas pelos profissionais de informação em Arte e suas instituições.

Trata-se de pesquisa de natureza exploratória, pois teve o objetivo de traçar um cenário do fenômeno estudado, que de acordo com Gil (2008, p. 27) é "[...] desenvolvida com objetivo de proporcionar visão geral, de tipo aproximativo, acerca de determinado fato" e descritiva. Tomou-se por base a abordagem qualitativa, como referência Minayo (2013, p. 57) "[...] as abordagens qualitativas foram utilizados 
análise documental, se conformam melhor as investigações de grupos e segmentos delimitados e focalizados, de histórias sociais sob a ótica dos atores, de relações e para a análise de discursos e de documentos." Por se tratar de um grupo de pessoas adotou-se o estudo de caso como método.

O predomínio foi da abordagem qualitativa, embora tenha sido utilizada a abordagem quantitativa (estatística - frequência absoluta e relativa) para tabular e apresentar os resultados do questionário enviado aos membros. Na perspectiva Minayo e Sanchez (1993) a utilização das duas abordagens (qualitativa e quantitativa) é considerada como complementar e não contraditória, devendo-se respeitar "seus significados mais essenciais".

Foram adotadas técnicas diferentes para a coleta dos dados: pesquisa documental, análise de site, observação de reuniões, questionário e entrevista.

O público-alvo da pesquisa foram os membros associados da REDARTE/RJ. Aos 31 afiliados da Rede em julho 2014, foi enviado um questionário com 45 assertivas, e foram recebidas 22 respostas, o que significou $71 \%$ de resultado. Também, realizaram-se entrevistas com a coordenadora e fundadora da Rede, bem como com a presidente do período 2012-2014.

Optou-se pela realização de quadros e gráficos para resumir os dados coletados, tais como Quadros referentes às características (o Domínio, a Comunidade e a Prática), indicadores e fatores de sucesso de CoP em relação ao resultado das assertivas do questionário respondidas pelos membros.

Os dados coletados no questionário, nas entrevistas e no levantamento documental foram interpretados sob a perspectiva teórica de Wenger, McDermott e Snyder (2002) para três características (o domínio, a comunidade e a prática); Wenger (1998) para os indicadores de CoP e McDermott (2001) para os fatores de críticos de sucesso de comunidades de prática. 


\section{ANÁLISE DOS RESULTADOS}

Trabalhar em rede necessariamente, não significa trabalhar somente com tecnologia. Algumas redes são essencialmente de pessoas que priorizam as relações interpessoais, a troca de experiências e o compartilhamento de conhecimento. Para estes indivíduos a tecnologia da informação é um instrumento que agiliza o processo de comunicação.

Segundo Castells (1999, p.498), as "[...] redes são estruturas abertas capazes de expandir de forma ilimitada, integrando novos nós desde que consigam comunicar-se dentro da rede."

Constata-se na literatura a existência de inúmeros tipos de rede, mas a rede objeto deste trabalho foi uma rede de bibliotecas, que segundo Valera Orol, Garcia Melero e Gonzalez Guitian (1988, p. 217) "[...] constituem um conjunto de sistema de bibliotecas, conectadas, mas mantêm sua administrativa; desta forma, a cooperação entre as bibliotecas é a essência da rede."

A Rede de Bibliotecas e Centros de Informação em Arte REDARTE/RJ foi uma idealização de Solange Zuñiga, na época, diretora Departamento de Pesquisa e Documentação da Fundação Nacional de Arte - FUNARTE, órgão do Ministério da Cultura. Coube a coordenação da rede ficou com Helena Dodd Ferrez, também, coordenadora do departamento de Documentação da mesma instituição.

Desde a primeira reunião, em 8 de dezembro de 1995, conforme conta em ata, Rede tem sua finalidade definida "Solange falou, inicialmente, sobre a ideia da rede cujo objetivo seria agilizar o trabalho de seus participantes e economizar custos (financeiros e humanos)"1. Compareceram ao primeiro encontro 15 participantes representantes de 11 instituições da esfera pública e particular que foram convidados.

\footnotetext{
${ }^{1}$ FERREZ, Helena Dodd. A REDARTE/RJ: entrevista. 27 julho 2014. Rio de Janeiro. Entrevista concedida a AUTOR
} 
Após dez anos de criada a Rede dobra o número de instituições associadas e busca formalizar sua existência, estabelecendo um estatuto. Enfim, a REDARTE/RJ é ocializada como associação civil sem fins lucrativos de natureza cultural.

Em seu estatuto, no ano 2014 (ano em que foi realizada a pesquisa), o objetivo da Rede era ampliar, para o público em geral e os pesquisadores de Arte em particular, as opções de acesso a todo um universo de informações disponível em um conjunto expressivo e representativo de acervos especializados em Arte, localizados nas cidades do Rio de Janeiro e em Niterói.

Cinco instituições permanecem associadas desde a criação da Rede quando eram onze instituições membro. São elas a FUNARTE/CEDOC, o Museu Histórico Nacional, o Museu Nacional de Belas Artes, o Museu de Arte Moderna/RJ e a UNIRIO/Centro de Letras e Artes).

Ao analisar o acervo documental da REDARTE/RJ verificou-se que a permanência dos associados oscila de acordo com 0 representante da instituição e a situação econômica-política-social do país. Em 2014, ano da pesquisa, eram 28 instituições associadas e 3 sócios colaboradores (pessoas físicas).

Os usuários dos produtos e dos serviços são os pesquisadores, estudantes e interessados em Arte das instituições integrantes da Rede.

Os representantes das instituições participantes são bibliotecários, museólogos, arquivista e historiadores. Nota-se que os 22 respondentes do questionário que serviu de base para pesquisa eram bibliotecários.

O questionário foi estruturado com cerca de 45 assertivas para os 31 representantes dos membros da Rede. Foram recebidas 22 respostas. Entende-se que $71 \%$ dos representantes dos membros da REDARDE/RJ atenderam ao pedido. Deve ser considerado que cinco instituições estavam sem representantes no período da aplicação do questionário e quatro pessoas não responderam. 
O resultado da pesquisa mostrou que os responsáveis pela Rede devem levar em consideração o fato da aposentadoria eminente da maioria dos representantes que responderam ao questionário. Dos 22 bibliotecários $68 \%$ deles trabalham na área a mais de 20 anos

\subsection{Difusão da REDARTE/RJ Entre as Bibliotecas de Arte}

A REDARTE/RJ pode ser considerada uma inovação na área de Informação em Arte, sendo considerada um sistema social (bibliotecas e centros de informação em Arte) que reúne um conjunto de unidades inter-relacionadas que de acordo com a ata de 1995 visa "agilizar o trabalho de seus participantes e economizar custos (financeiros e humanos)" na solução de um problema e na busca para atingir uma meta comum.

A partir da primeira reunião a participação de outras bibliotecas foi estimulada pelo boca a boca.. Por ocasião da pesquisa observou-se que o processo de difusão da rede também é realizado por intermédio das redes sociais.

O processo de difusão de inovações a partir da inovação é considerado dividido em dois momentos difusão e expansão (ROGERS, 2003). Considerando-se a REDARTE/RJ uma inovação organizacional a incorporação de novas bibliotecas à rede pode ser analisada como um processo de difusão de inovações.

Fazer da ameaça que era carência de recursos, uma oportunidade de inovar na criação da Rede está presente na idealização e na proposição do convite por parte de Solange Zuñiga da FUNARTE, ao convidar para a coordenação de Helena Ferrez da mesma instituição. Em resumo, verifica-se que o objetivo era ampliar o acesso à informação em Arte no Estado do Rio, pois todas estavam dispersas e muito "carentes de atenção".

O marco para a difusão da Rede ocorre por ocasião do final da primeira reunião com 11 (onze) membros realizada dezembro 1995, quando a coordenadora Helena Ferrez, solicita que os colegas 
"identifiquem e convidem outros colegas para a próxima reunião". A partir daí, fica estabelecido o compromisso de difusão da Rede.

A expansão da Rede é observada ao longo de sua trajetória e o número de associados tem permanecido em torno do total atingido ao final de 1996 que são 28 (vinte e oito) membros. As instituições às quais as bibliotecas fazem parte são de natureza pública e privada sendo sujeitas as oscilações sócio-político-econômica ocorridas no contexto brasileiro e do estado do Rio de Janeiro. Após 2006, quando ocorre a oficialização da rede como uma associação civil de natureza cultural, estruturada como uma organização verifica-se a ampliação da área de atuação da REDARTE/RJ, pois a rede passa a ter condições de diversificar seus produtos (site e redes sociais) e serviços (consultoria e assessoria) para as bibliotecas associadas. Em 2014, constou-se 28 bibliotecas participantes e 3 sócios colaboradores.

\subsection{Comunidades de prática e a REDARTE/RJ: Características Comuns}

O material coletado para subsidiar a pesquisa da qual o presente artigo é um extrato, revelou conteúdo muito rico. A análise, a apreciação e a interpretação dos dados foi realizada de modo a extrair das respostas das 45 assertivas, pesquisa documental e das entrevistas 0 que poderia ser entendido como característica, indicador e fatores de sucesso de comunidades de prática.

Como o questionário foi estruturado sob a escala de concordância de Likert, levou-se em consideração o somatório das respostas para concordo totalmente e concordo para cada assertiva.

Ressalta-se que a subjetividade do tema comunidades de prática permite inúmeras interpretações. Sendo assim, as autoras apresentam uma síntese onde agrupam as características, indicador e fatores de sucesso de $\mathrm{CoP}$ e procuram relacionar às assertivas do questionário enviados aos membros da REDARTE/RJ. 
De acordo com Wenger, McDermott e Snyder (2002) pode-se dizer o domínio significa ter uma identidade definida pelo compartilhamento de interesse(s) por pares comprometidos e um grau de confiança estabelecido ao longo do tempo. O Quadro 1 apresenta uma síntese das respostas recebidas e sua relação com os aspectos de comunidades de prática.

Quadro 1 - Característica: o domínio

\begin{tabular}{|c|c|c|c|c|}
\hline $\begin{array}{l}\text { Característic } \\
\text { as de CoP } \\
\text { (WENGER, } \\
\text { McDERMOTT } \\
\text {; SNYDER, }\end{array}$ & $\begin{array}{l}\text { Indicadores } \\
\text { de CoP } \\
\text { (WENGER, } \\
\text { 1998) }\end{array}$ & $\begin{array}{c}\text { Fatores de } \\
\text { Sucesso de CoP } \\
\text { (McDERMOTT, } \\
\text { 2001) }\end{array}$ & $\begin{array}{c}\text { Assertivas } \\
\text { (REDART/RJ) }\end{array}$ & $\begin{array}{l}\text { Frequência } \\
\text { Relativa }\end{array}$ \\
\hline \multirow{4}{*}{ O Domínio } & \multirow{2}{*}{$\begin{array}{l}\text { Conhecer o que } \\
\text { os outros } \\
\text { sabem, o que } \\
\text { eles podem } \\
\text { fazer, e como } \\
\text { eles podem } \\
\text { contribuir para } \\
\text { uma empresa }\end{array}$} & \multirow{2}{*}{$\begin{array}{l}\text { Domínio e objetivo } \\
\text { da comunidade } \\
\text { (Desafio Gestão) }\end{array}$} & $\begin{array}{l}\text { Acredito que a } \\
\text { REDARE/RJ } \\
\text { criou uma } \\
\text { imagem/marca } \\
\text { na área de } \\
\text { informação }\end{array}$ & $81 \%$ \\
\hline & & & $\begin{array}{l}\text { Considero o } \\
\text { Estatuto da } \\
\text { REDARTE/RJ } \\
\text { norteador dos } \\
\text { padrões da rede }\end{array}$ & $86 \%$ \\
\hline & \multirow{2}{*}{$\begin{array}{l}\text { Um discurso } \\
\text { compartilhado } \\
\text { refletindo uma } \\
\text { certa } \\
\text { perspectiva } \\
\text { sobre o mundo }\end{array}$} & $\begin{array}{l}\text { Patrocínio (Desafio } \\
\text { Gestão) }\end{array}$ & $\begin{array}{l}\text { Existe } \\
\text { reconhecimento } \\
\text { por parte dos } \\
\text { meus superiores } \\
\text { da importâncai } \\
\text { de minha } \\
\text { participação da } \\
\text { REDARTE/RJ }\end{array}$ & $85 \%$ \\
\hline & & Desafio Pessoal & $\begin{array}{l}\text { Acredito que a } \\
\text { REDARTE/RJ } \\
\text { contribui para } \\
\text { abrir mais } \\
\text { espaços de } \\
\text { atuação para os } \\
\text { profissionais de } \\
\text { informação em } \\
\text { Arte }\end{array}$ & $77 \%$ \\
\hline
\end{tabular}

Fonte: Autoria própria.

No Quadro 1 foram selecionados resultados que comprovam a existência da característica domínio na REDARTE/RJ.

Pode-se constatar que $81 \%$ (63\% concordam totalmente e 18\% concordam) dos respondentes percebem que a REDARTE/RJ criou uma marca na área de Informação em Arte, evidenciando um discurso compartilhado sobre a forma pela qual a rede se insere no mundo social. 
Este aspecto também é salientado desde o surgimento da rede, pois esta se destaca no cenário de Informação em Arte "[...] à medida que fomos ganhando certa visibilidade, bem modesta, digam-se de passagem, outras bibliotecas começaram a querer fazer parte, embora muitas não se encaixassem no perfil da Rede". ${ }^{2}$

Comprova-se que para os $82 \%$ a Rede possui indicadores de CoP, como "o embasamento é comum a todos" e "Legitima a comunidade por afirmar seus propósitos e trazendo valor para os membros e as partes interessadas (WENGER, 1998, p. 125-126). Ao procurar "alinhamento com a estratégia da instituição do desafio gestão" defendido por McDermott (2001) quando os representantes das instituições buscam patrocínio junto aos seus superiores.

Evidencia-se como pontos fortes da característica domínio na Rede: seu Estatuto, a identidade, as parcerias, a visibilidade que os integrantes conquistam entre os profissionais da informação e seus superiores institucional, e consequentemente, o patrocínio.

A característica de CoP, a comunidade, está refere-se a uma relação construída que permite um aprendizado contínuo; desenvolvem sentimento de pertencer a algo em comum que contribua para melhoria de suas atividades.

Representa-se no Quadro 2 um resumo do resultado das assertivas que foram correlacionadas à característica comunidade.

\footnotetext{
${ }^{2}$ FERREZ, Helena Dodd. A REDARTE/RJ: entrevista. 27 julho 2014. Rio de Janeiro. Entrevista
} concedida a AUTOR. 
Quadro 2 - Característica: a comunidade

\begin{tabular}{|c|c|c|c|c|}
\hline $\begin{array}{c}\text { Característic } \\
\text { as de CoP } \\
\text { (WENGER, } \\
\text { McDERMOT } \\
\text { T; SNYDER, } \\
\text { 2002) }\end{array}$ & $\begin{array}{c}\text { Indicadores } \\
\text { de CoP } \\
\text { (WENGER, } \\
\text { 1998) }\end{array}$ & $\begin{array}{c}\text { Fatores de } \\
\text { Sucesso de } \\
\text { CoP } \\
\text { (McDERMOTT, } \\
\text { 2001) }\end{array}$ & $\begin{array}{c}\text { Assertivas } \\
\text { (REDART/RJ) }\end{array}$ & $\begin{array}{c}\text { Frequência } \\
\text { Relativa }\end{array}$ \\
\hline \multirow{4}{*}{ A Comunidade } & $\begin{array}{l}\text { A } \\
\text { sustentabilidade } \\
\text { das relações } \\
\text { mútuas - } \\
\text { harmoniosas ou } \\
\text { conflituosas }\end{array}$ & $\begin{array}{l}\text { Confiança } \\
\text { (Desafio de } \\
\text { Comunidade) }\end{array}$ & $\begin{array}{l}\text { Percebo que o } \\
\text { compromisso, } \\
\text { colaboração e o } \\
\text { compartilhament } \\
\text { o é uma regra } \\
\text { implícita nas } \\
\text { ações da } \\
\text { REDARTE/RJ }\end{array}$ & $76 \%$ \\
\hline & $\begin{array}{l}\text { Identidades } \\
\text { mutuamente } \\
\text { definidas }\end{array}$ & $\begin{array}{l}\text { Especialistas da } \\
\text { área de } \\
\text { conhecimento } \\
\text { (Desafio da } \\
\text { Comunidade) }\end{array}$ & $\begin{array}{l}\text { Os membros da } \\
\text { REDARTE/RJ } \\
\text { conhecem e } \\
\text { reconhecem o } \\
\text { seu papel }\end{array}$ & $73 \%$ \\
\hline & $\begin{array}{l}\text { A sabedoria } \\
\text { local, histórias } \\
\text { compartilhadas, } \\
\text { etc. }\end{array}$ & $\begin{array}{l}\text { Sentimento de } \\
\text { pertença (Desafio } \\
\text { da Comunidade) }\end{array}$ & $\begin{array}{l}\text { Existe entre os } \\
\text { membros da } \\
\text { REDARTE/RJ } \\
\text { um clima de } \\
\text { confiança e } \\
\text { credibilidade na } \\
\text { informação } \\
\text { gerada e } \\
\text { compartilhada }\end{array}$ & $81 \%$ \\
\hline & $\begin{array}{l}\text { Certos estilos } \\
\text { reconhecidos } \\
\text { como a } \\
\text { indicação de } \\
\text { membros }\end{array}$ & $\begin{array}{l}\text { Encontre um } \\
\text { membro da } \\
\text { comunidade bem } \\
\text { respeitado para } \\
\text { coordenar a CoP } \\
\text { (Desafio da } \\
\text { Gestão) }\end{array}$ & $\begin{array}{l}\text { As tomadas de } \\
\text { decisões na } \\
\text { REDARTE/RJ } \\
\text { são pautadas } \\
\text { em definições } \\
\text { dos membros da } \\
\text { rede }\end{array}$ & $85 \%$ \\
\hline
\end{tabular}

Fonte: Autoria própria.

Verifica-se que 79\% das características da REDARTE/RJ são atributos de comunidades de prática. Comprova-se que o compromisso, a colaboração e o compartilhamento tem sido inerente aos integrantes da Rede, o que se reflete na sua sustentabilidade (WENGER, 1998, p.125-126). Tais sentimentos são expressos por Ferrez (2014) quando convidada a definir a REDARTE/RJ "acho que o principal objetivo era essa comunhão entre os bibliotecários"3.

Conforme os estudos realizados por Wenger (1998) o sentimento de pertença é relevante para o sucesso de uma comunidade de prática.

${ }^{3}$ Idem. 
Constata-se que $81 \%$ dos respondentes estão imbuídos de confiança na REDARTE/RJ e nas informações propagadas na Rede.

A confiança é um fator de sucesso descrito por McDermott (2001) no desafio da Comunidade e encontra-se presente na REDARTE/RJ quando Ferrez (2014) confessa "para mim era um grupo muito "gostoso", que foi criando laços de amizade e de ajuda mútua. É isso. Não queríamos muito mais que isso, até porque era algo que acontecia exclusivamente por iniciativa de seus membros"4.

A REDARTE/RJ apresenta pontos fortes quanto à característica comunidade, tais como: o compromisso, o orgulho e o sentimento de pertença, seus membros estão aberto a novos produtos e serviços.

A prática é a característica contribui para evolução da Rede. No Quadro 3 foram relacionadas às assertivas mais pertinentes a esta característica.

\footnotetext{
${ }^{4}$ FERREZ, Helena Dodd. A REDARTE/RJ: entrevista. 27 julho 2014. Rio de Janeiro. Entrevista concedida a AUTOR.
} 
Quadro 3 - Característica: a prática

\begin{tabular}{|c|c|c|c|c|}
\hline $\begin{array}{c}\text { Característi } \\
\text { cas de CoP } \\
\text { (WENGER, } \\
\text { McDERMO } \\
\text { TT; } \\
\text { SNYDER, } \\
\text { 2002) }\end{array}$ & $\begin{array}{c}\text { Indicadore } \\
\text { s de CoP } \\
\text { (WENGER, } \\
\text { 1998) }\end{array}$ & $\begin{array}{c}\text { Fatores de } \\
\text { Sucesso de CoP } \\
\text { (McDERMOTT, } \\
\text { 2001) }\end{array}$ & $\begin{array}{c}\text { Assertivas } \\
\text { (REDART/RJ) }\end{array}$ & $\begin{array}{c}\text { Frequência } \\
\text { Relativa }\end{array}$ \\
\hline \multirow{4}{*}{ A Prática } & \multirow[b]{2}{*}{$\begin{array}{l}\text { Formas } \\
\text { compartilhad } \\
\text { as de } \\
\text { engajar-se e } \\
\text { fazer as } \\
\text { coisas } \\
\text { juntos; }\end{array}$} & $\begin{array}{l}\text { Alinhamento com a } \\
\text { estratégia da Rede } \\
\text { (Desafio da Gestão) }\end{array}$ & $\begin{array}{l}\text { Oriento meus } \\
\text { usuários a } \\
\text { utilizarem os } \\
\text { recursos da } \\
\text { REDARTE/RJ }\end{array}$ & $72 \%$ \\
\hline & & $\begin{array}{l}\text { Alinhamento com a } \\
\text { estratégia da Rede } \\
\text { (Desafio da Gestão }\end{array}$ & $\begin{array}{l}\text { Indico e recorro } \\
\text { aos produtos } \\
\text { (Biblioteca Digital, } \\
\text { Guia de } \\
\text { Fornecedores, } \\
\text { Guia de } \\
\text { Bibliotecas em } \\
\text { Arte) da } \\
\text { REDARTE/RJ } \\
\text { para atender } \\
\text { meus usuários }\end{array}$ & $72 \%$ \\
\hline & \multirow{2}{*}{$\begin{array}{l}\text { Ferramentas } \\
\text { específicas, } \\
\text { representaçõ } \\
\text { es e outros } \\
\text { artefatos }\end{array}$} & \multirow{2}{*}{$\begin{array}{l}\text { Tornar mais fácil para } \\
\text { contribuir e acessar } \\
\text { conhecimento } \\
\text { (Desafio Técnico) }\end{array}$} & $\begin{array}{l}\text { Recorro aos } \\
\text { catálogos das } \\
\text { instituições } \\
\text { membros da } \\
\text { REDARTE/RJ } \\
\text { para atender } \\
\text { meus usuários }\end{array}$ & $81 \%$ \\
\hline & & & $\begin{array}{l}\text { O site da } \\
\text { REDARTE/RJ } \\
\text { atende as } \\
\text { necessidades } \\
\text { informacionais } \\
\text { dos usuários de } \\
\text { minha instituição }\end{array}$ & $68 \%$ \\
\hline
\end{tabular}

Fonte: As Autoras

A característica prática diz respeito à rotina dos profissionais que no seu fazer diário trocam experiências, utilizam instrumentos informacionais semelhantes e desenvolvem produtos e serviços em suas instituições.

Percebe-se que no percentual de respostas dividido pelo número de assertivas neste quesito, a REDARTE/RJ alcança 73\% da característica prática defendida pelos especialistas. Os profissionais utilizam e incentivam seus usuários a utilizarem o catálogo da Rede. Um número expressivo de respondentes está satisfeito com o website.

Os recursos de tecnologia da informação são utilizados como meio para ampliar a comunicação entre os membros como salienta Ferrez (2014) desde o início “... a nossa rede [REDARTE/RJ] não teria a 
tecnologia como fator determinante" . A combinação dos dois mundos é o que se observa na Rede, pode-se afirmar que a tecnologia facilita a interação entre os membros de uma comunidade, como ressalta Wenger (2006) "o conhecimento existe na comunidade e a comunidade são as pessoas, então a tecnologia é utilizada como suporte à comunidade."

No que se refere à característica prática a Rede possui pontos fortes que são o seu diferencial, tais como: empréstimo entre instituições, melhoria do trabalho no dia-a-dia, site que disponibiliza acesso à biblioteca digital e guia de fornecedores da área de informação em Arte, uso de e-mail entre outras práticas.

A seguir apresenta-se no Gráfico 1 um resumo do percentual de cada característica de comunidade de prática existente nas atividades, produtos e serviços da REDARTE/RJ.

\section{Gráfico 1 - Características de CoP na REDARTE/RJ}

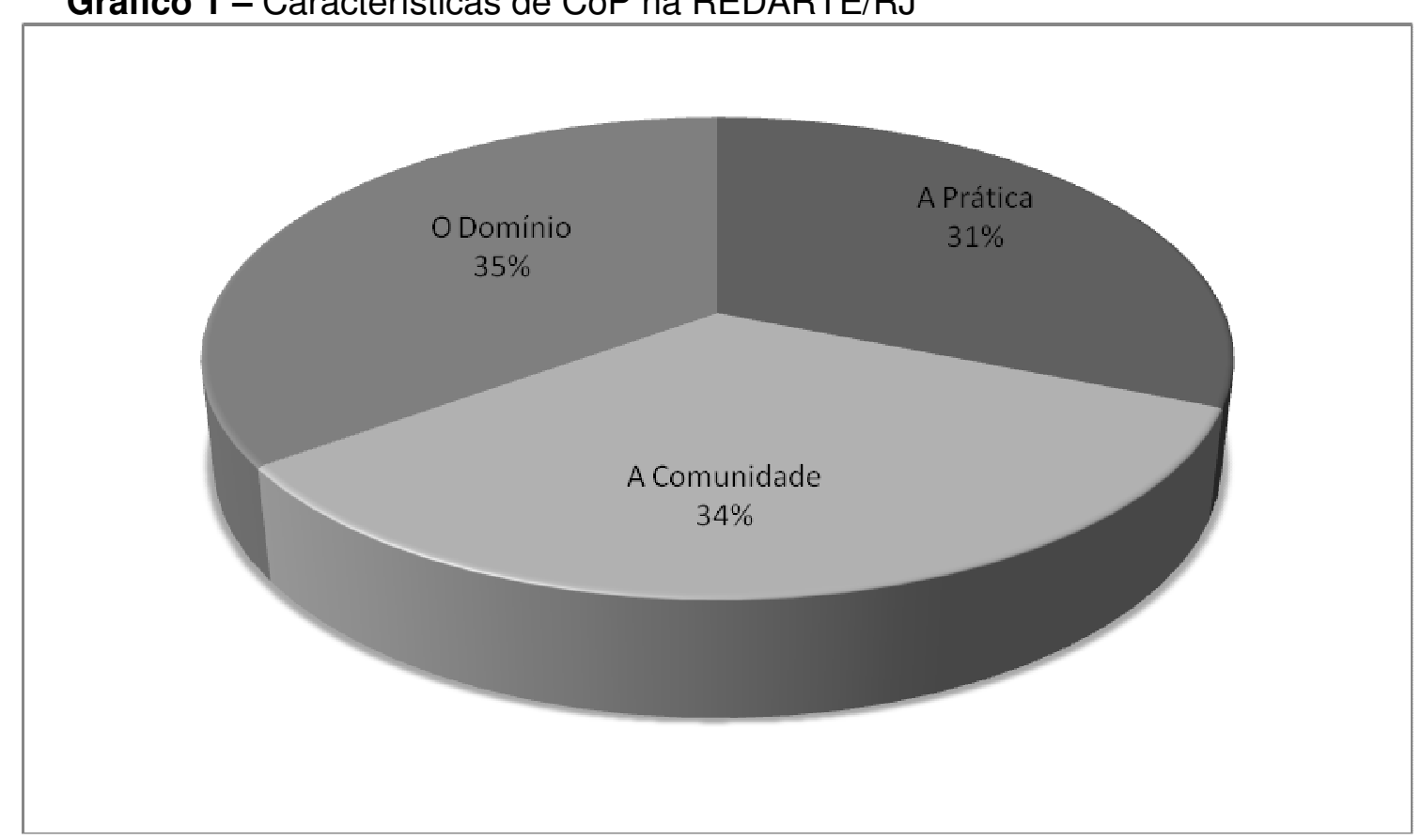

Fonte: As Autoras

Comprova-se que a REDART/RJ é uma rede que apresenta muita das características, indicadores e fatores de sucesso de comunidades de prática.

${ }^{5}$ Idem. 
Para ampliar a dinâmica da Rede e incrementar suas atividades foram elaboradas algumas recomendações apresentadas a seguir:

1. o planejamento estratégico deve contemplar um plano de comunicação que contenha kit diferenciado com benefícios e obrigações para novos membros, patrocinadores e parceiros;

2. incentivar aos membros para o uso dos instrumentos de redes sociais, tais como os recursos mensagens instantâneas (criar grupos), ampliar utilização do Facebook, Picasa e outros;

3. programar de dois a três encontros (workshop) anuais para alinhamento dos membros (WENGER; MCDERMOTT; SNYDER, 2002, p. 130);

4. utilizar a técnica de lições aprendidas do Project Management Body of Knowledge (PMBOK) pode colaborar para a construção de uma base de conhecimento;

5. estruturar uma base de conhecimento para preservar as práticas positivas e as que requerem melhorias, histórias de sucesso e a memória da rede;

6. organizar de um "páginas amarelas" dos profissionais que atuam e já atuaram na REDARTE/RJ, mais conhecido como "quem é quem" na área de Informação em Arte;

7. aproveitar os benefícios de parceria com entidades de classe como a Federação Brasileira de Bibliotecários, Cientistas da Informação e Instituições - FEBAB;

Segundo Melo (2015) "[...] como a temática tratada pelos membros da REDARTE/ RJ é a Arte nas suas mais diversas formas de expressão, isto é, uma rede interdisciplinar, propõe-se que procure estabelecer parcerias com instituições de ensino." A interação com universidades poderá propiciar aporte em agências de fomento seja para projetos de extensão ou de desenvolvimento de pesquisas conjuntas.

\section{CONSIDERAÇÕES FINAIS}

Embora respeitando as diferenças nas estruturas de rede e comunidades pratica o estudo identificou percentual significativo das características, indicadores e fatores de comunidades de prática na REDARTE/RJ. 
Verifica-se que o presente trabalho atingiu seu objetivo, apresentou uma síntese de pesquisa que identificou e analisou quais características da Rede de Bibliotecas e Centros de Informação em Arte no Estado do Rio de Janeiro (REDARTE/RJ) se assemelham às de comunidades de prática (CoP) e, verificou se as características identificadas podem contribuir para a maior integração das ações desenvolvidas pelos profissionais de informação em Arte e suas instituições. Conclui-se que a REDARTE/RJ possui as características e indicadores de comunidades de prática quando apresenta nos exemplos ilustrados o resultado para as características: o domínio conta 82,\%, a comunidade $79 \%$ e a prática $73 \%$. Também, observa-se que determinadas práticas utilizadas em CoP podem ser empregadas na dinamização das práticas da REDARTE/RJ.

O resultado demonstra que a Rede pode se apropriar de dinâmicas utilizadas em CoP como encontros para os membros nivelar seus conhecimentos, a promoção de eventos de lições aprendidas, ampliar a divulgação intra e extramuros com um plano de comunicação eficiente.

A teoria de comunidade de prática aplicada na investigação da REDARTE/RJ mostrou que a aprendizagem coletiva pode fortalecer em determinadas área, desde que seja formado por um grupo de pessoas em que existe cumplicidade, comprometimento, compartilhamento, preocupação em fazer e crescer juntos. Estes são os fatores que contribuem para a trajetória de quase 20 anos de sucesso da REDARTE/RJ.

Em termos de difusão a REDARTE/RJ encontra-se na etapa da expansão, pois trabalham na ampliação de suas atividades, produtos e serviços; bem como, trabalha na conquista de mais parcerias e novos membros. 


\section{REFERÊNCIAS}

CASTELLS, Manuel. A sociedade em rede. São Paulo: Paz e Terra, 1999.

FERREZ, Helena Dodd. A REDARTE/RJ: entrevista. 27 julho 2014. Rio de Janeiro. Entrevista concedida a AUTOR.

GIL, Antonio Carlos. Métodos e técnicas de pesquisa social. 6. ed. São Paulo: Atlas, 2008.

INTERNATIONAL FEDERATION OF LIBRARY ASSOCIATIONS AND INSTITUTIONS. Knowledge Management section. What is Knowledge Management? Disponível em:

$<$ http://iflakm.wikispaces.com/What+is+Knowledge+Management\%3F?re sponseToken=011563dfe66259f2024e88ebf9986c78c $>$. Acesso em: 28 set. 2014.

McDERMOTT, Richard. Knowing in Community: 10 Critical Success Factors in Building Communities of Practice. 2001. Disponível em: <http://archive2.nmc.org/projects/dkc/sfccp_1.shtml>. Acesso em: 19 ago. 2015.

MINAYO, Maria Cecília de Souza. O desafio do conhecimento: pesquisa qualitativa em saúde. 13. ed. São Paulo: Hucitec, 2013.

MINAYO, Maria Cecilia de S., SANCHES, Odécio. QuantitativoQualitativo: Oposição ou Complementaridade? Cad. Saúde Públ., Rio de Janeiro, v. 9 n. 3, p. 239-262, jul/set, 1993. Disponível em: $<$ http://unisc.br/portal/upload/com_arquivo/quantitavivo_qualitativo_oposi cao_ou_complementariedade.pdf>. Acesso em: 16 out. 2015.

OECD. Manual de Oslo: diretrizes para coleta e interpretação de dados sobre inovação. 3. ed. Rio de Janeiro: FINEP, 1997. Disponível em:<http://www.uesc.br/nucleos/nit/manualoslo.pdf>. Acesso em: 17 jul. 2015.

PINHEIRO, Lena Vania Ribeiro; GONZALEZ DE GOMEZ, Maria Nélida (Org.). Interdiscursos da ciência da informação: arte, museu e imagem. Rio de Janeiro; Brasília: IBICT/DEP/DDI, 2000.

REDES DE BIBLIOTECAS E CENTROS DE INFORMAÇÃO EM ARTE ARTE NO ESTADO DO RIOI DE JANEIRO - REDARTE/RJ. Atas. Rio de Janeiro, 1995-1997, 2005-2007, 2010-2014. Mimeo.

Estatuto. Rio de Janeiro, 2011. Disponível em: 
<http://redarterj.com/estatuto/>. Acesso em: 26 jan. 2015.

ROGERS, Everett. Diffusion of Innovations. 3 ed. New York: Free Press, 1983.

ROGERS, Everett. Diffusion of Innovations. 5 ed. New York: Free Press, 2003.

SPECIAL LIBRARIES ASSOCIATION. Competencies for Information Professionals of the $21^{\text {st }}$ Century. 2003. Disponível em:

$<$ http://sla.org/wp-

content/uploads/2013/01/0_LRNCompetencies2003_revised.pdf>.

Acesso em: 10 set. 2015.

TERRA, José Claudio C. Gestão do Conhecimento: 7 dimensões e 100 práticas gerenciais. 2007. Disponível em:

<http://biblioteca.terraforum.com.br/BibliotecaArtigo/GC_7_Dimens\%C3 \%B5es_e_100_pr\%C3\%A1ticas_gerenciais.pdf>. Acesso em: 06 jun. 2014.

TOWNLEY, Charles T. KM and academic libraries. C\&RL, v. 62, n. 144, p.44-55, Jan. 2001. Disponível em:

<http://crl.acrl.org/content/62/1/44.full.pdf+html>. Acesso em: 4 fev.

2014.

VALERA OROL, Concha Varela; GARCIA MELERO, Luis Angel; GONZALEZ GUITIAN, Carlos Gonzalez. Redes de bibliotecas. Boletín de La Anabad, A Conuña, v. 38, n. 1-2, p.215-242, 1988. Disponível em: <http://biblio.universia.es/catalogos-recursos/redes-debiblioteca/redes-bibliotecas.pdf>. Acesso em: 15 set. 2015.

WENGER, Etienne. Communities of practice: learning, meaning, and identity. Cambridge, UK: University of Cambridge Press, 1998.

WENGER. Etienne. Communities of practice and social learning systems: the career of a concecpt. 2010. Disponível em: $<$ http://wenger-trayner.com/wp-content/uploads/2012/01/09-10-27-CoPsand-systems-v2.0.pdf>. Acesso em: 21 set. 2015.

WENGER, Etienne; McDEMORTT, Richard; SNYDER, William.

Cultivating communities of practice: a guide to managing knowledge. Boston: Harvard Business Press, 2002. 


\section{Title}

Communities of practice: a case study Redarte / RJ

\section{Abstract}

Introduction: This article is based on part of the master's Communities of practice dissertation research results: a case study in the Network of Libraries and Information Centers in Art in the State of Rio de Janeiro - REDARTE / RJ.

Objective: Shows that networks play an increasingly important role in society. Aimed at identifying and analyzing which network characteristics of Libraries and Information Centers in Art in the State of Rio de Janeiro (REDARTE / RJ) resemble those of communities of practice (CoP) and, if so, check whether the observed characteristics can contribute to greater integration of actions developed by information professionals in art and its institutions.

Methodology: Case study based on a survey of descriptive and exploratory qualitative and quantitative approach used for data collection desk research, interview and questionnaire. Identifies strengths and areas for improvement.

Results: It appears that the REDARTE / RJ can be characterized as a community of practice because it has the essential characteristics of this type of organization: the domain, community and practice in their activities, products and services.

Conclusions: The strengths and improvement are identified and recommendations are presented CoP of strategies to improve the network's actions.

Keywords: Communities of practice. Knowledge management. Information Art. Networks of libraries. Information centers. REDARTE/RJ.

\section{Titulo}

Comunidades de práctica: un estudio de caso Redarte / RJ

\section{Resumen}

Introducción: Este artículo se basa en parte de resultados de la investigación de tesis Comunidad de practica: un estudio de caso de la Red de Bibliotecas y Centros de Información en Arte en el Estado de Río de Janeiro REDARTE/RJ.

Objetivo: Muestra que las redes juegan un papel cada vez más importante en la sociedad. Cuyo objetivo fue identificar y analizar qué características de la red de Bibliotecas y Centros de Información en Arte en el Estado de Río de Janeiro (REDARTE / RJ) se asemejan a los de las comunidades de práctica (CoP) y, si es así, comprobar si las características observadas puede contribuir a una mayor integración de las acciones desarrolladas por profesionales de la información en el arte y sus instituciones.

Metodología: Estudio de caso sobre la base de un estudio de abordaje cualitativo y cuantitativo descriptivo y exploratorio utilizado para la investigación documental de recopilación de datos, la entrevista y el cuestionario. Identifica los puntos fuertes y áreas de mejora. 
Resultados: Parece ser que el REDARTE / RJ puede ser caracterizado como una comunidad de práctica, ya que tiene las características esenciales de este tipo de organización: el dominio, la comunidad y la práctica de sus actividades, productos y servicios.

Conclusión: Las fortalezas y mejora se identifican y recomendaciones se presentan CoP de estrategias para mejorar las acciones de la Red.

Palabras claves: Comunidades de práctica. La gestión del conocimiento. Arte de la Información. Redes de bibliotecas. Los centros de información. REDARTE/RJ.

Recebido em: 10.10.2015

Aceito em: 20.12.2015 